\title{
Volatile compounds of fresh and processed garlic (Review)
}

\author{
KAZUKI ABE $^{1,2}$, YOJI HORI ${ }^{1}$ and TAKAO MYODA ${ }^{1}$ \\ ${ }^{1}$ Laboratory of Aroma Chemistry, Department of Food and Cosmetic Science, Faculty of Bioindustry, \\ Tokyo University of Agriculture, Abashiri, Hokkaido 099-2493; ${ }^{2}$ Healthcare Research and Development Division, \\ Wakunaga Pharmaceutical Co. Ltd., Akitakata, Hiroshima 739-1195, Japan
}

Received August 12, 2019; Accepted September 26, 2019

DOI: $10.3892 /$ etm.2019.8394

\begin{abstract}
Garlic is used as a spice in cooking due to its unique aroma. The unique aroma of garlic has attracted considerable attention from scientists. The cloves contain large amounts of sulfur-based substances, which as a consequence of their reactive properties, are converted easily to a variety of volatile compounds during processing. The volatile profiles of processed garlic are influenced by processing conditions, such as temperature, $\mathrm{pH}$ and solvent. Numerous studies on these changes in volatile compounds that occur during processing have been reported, with a number of types of sulfur-containing volatile compounds being identified in fresh and processed garlic. This review summarizes the volatile components of fresh and processed garlic, particularly those produced by heating and aging. The pungent odor of fresh garlic is contributed mainly to thiosulfinates and their degradation products. During the heating process of garlic, thiosulfinates are mainly decomposed, and nitrogen-containing volatile compounds, such as pyridines and pyrazines are generated. Aldehydes are dominant compounds in black garlic, while esters and phenols are key aroma compounds in aged garlic extract. The slight variations in chemical reactions during the aging process may lead to differences in the aroma of the two types of garlic.
\end{abstract}

\section{Contents}

1. Introduction

2. Volatile components of raw garlic cloves

3. Nature of volatile compounds in garlic cloves during heating

4. Comparison of volatile components between black garlic and aged garlic extract

5. Conclusion

Correspondence to: Dr Takao Myoda, Laboratory of Aroma Chemistry, Department of Food and Cosmetic Science, Faculty of Bioindustry, Tokyo University of Agriculture, 196 Yasaka, Abashiri, Hokkaido 099-2493, Japan

E-mail: t1myouda@nodai.ac.jp

Key words: garlic, aged garlic extract, organosulfur compounds, gas chromatography, aroma chemistry

\section{Introduction}

Garlic (Allium sativum L.) is a bulbous plant that is used widely as an ingredient in traditional cooking and also for medicinal purposes, as it is a rich source of carbohydrates and protein, and contains large amounts of sulfur-based substances (1). Garlic was used by the Egyptians in several therapeutic formulas, and by the Greeks and Romans as a healing agent (2).

The first scientific studies on garlic were reported by Louis Pasteur, who attributed the plant as having anti-bacterial properties (2). Studies have also reported that garlic extracts have antioxidant (3), anti-microbial (4) and anti-asthmatic effects (5), with current attention focusing on its cancer preventive properties (6-8).

The unique aroma of garlic has also attracted considerable attention from scientists. Fresh garlic contains alliin [S-3(2-propenylsulfinyl) ${ }_{\mathrm{L}}$-alanine-], an odorless derivative of cysteine. When fresh garlic is crushed, alliinase can convert alliin to allicin ( $S$-allyl 2-propene-1-sulfinothioate), that represents the characteristic odor of crushed fresh garlic (9). Other precursors of fresh aroma, such as $S$-methylcysteines $S$-oxide, $S$-(E)-1-propenylcysteine $S$-oxide and $\gamma$-glutamylalk(en)ylcysteines are found in intact garlic cloves (10-16). During the storage of the cloves, these $\gamma$-glutamylalk(en)ylcysteines can be converted into related alk(en)ylcistein $S$-oxides (14), and following disruption, these alk(en)ylcistein $S$-oxides are converted enzymatically into related alk(en)yl thiosulfinates, the primary aroma compounds of raw garlic.

This review summarized the volatile components of fresh garlic and changes in their composition and characteristics during thermal processing. The aroma of aged garlic, induced by soaking in ethanol at a low temperature, as well as the storage of bulbs at high temperatures under moisture-controlled conditions are also discussed.

\section{Volatile components of raw garlic cloves}

Table I presents the volatile compounds in raw and heated garlic cloves obtained by various extraction methods. A total of 85 sulfur containing compounds and 40 non-sulfur-containing have been reported in different studies. Thiosulfinates, such as allicin are reactive molecules and can undergo a number of transformations, including organosulfur compounds, such 
Table I. Volatile components in fresh garlic and heated garlic.

Compound $\quad$ Fresh garlic (Refs.)

Heated garlic (Refs.)

Thiols

Allylthiol

$(44,45,47,51,52)$

$(38,45,51,54)$

1,3-Benzedithiol

1,2-Dimercaptocyclopentane

Methanethiol

1-Methylimidazole-2-thiol

Thiosulfinates

Methane methyl thiosulfinate

Monosulfides

Allyl 2,3-epoxypropylsulfide

Allyl methyl sulfide

$(17,24,44-47,50,51)$

Allyl 1-propenyl sulfide

(44)

Allyl propyl sulfide

Butyl 1-propenyl sulfide

Cyclopentyl hexyl sulfide

Diallyl sulfide

Dimethyl sulfide

Di(1-propenyl) sulfide

Dipropyl sulfide

Ethyl vinyl sulfide

Methyl allyl thioacetate

3-Methyl-1,1-bis(methylthio)-1,3-butadiene

Methyl 2-propynyl sulfide

Methylthiocyclohexane

Methylthiocyclopentane

3-(Methylthio)penta-2,4-dione

5-(Methylthio)-4-penten-2-ol

3-Methylthio propanal

N-Morpholinomethyl isopropyl sulfide

1-Propenyl propyl sulfide

$(17,24,44,46,47,49-51)$

(44-46)

(44)

$(38,45,51,53,54)$

$(38,53)$

Disulfides

Allyl methyl disulfide

Allyl 1-propenyl disulfide

Allyl propyl disulfide

Diallyl disulfide

$(17,24,26,44-52)$

Dimethyl disulfide

Di(1-propenyl) disulfide

$(17,24,44-47,49,50)$

Methyl 1-propenyl disulfide

$(17,44,47,50)$

Methyl propyl disulfide

$(17,24,45-47,49)$

$(38,51,53,54)$

Polysulfides

Allyl methyl trisulfide

Allyl 1-propenyl trisulfide

$(17,44,46-51)$

(50)

Diallyl tetrasulfide

$(24,44,46,48,49)$

Diallyl trisulfide

Dimethyl tetrasulfide

$(17,24,26,44,46-52)$

$(47,49,50)$

Dimethyl trisulfide

Dipropyl trisulfide

$(17,44,46-50)$

$(38,54)$

$(34,38,45,51,53,54)$

$(38,45,51,54)$

$(38,54)$

$(38,54)$

$(38,51,54)$

(50)

Methyl butyl trisulfide

Methyl 1-propenyl trisulfide

Methyl propyl trisulfide 
Table I. Continued.

\section{Compound}

Cyclic sulfides

Benzothiophene

Cyclopentathiazole

3,5-Diethyl-1,2,4-trithiolane

4,5-Dimethylisothiazole

2,4-Dimethylthiazole

2,4-Dimethylthiophene

2,5-Dimethylthiophene

3,4-Dimethylthiophene

3,5-Dimethyl-1,2,4-trithiolane

1,2-Dithiacyclopentane

1,3-Dithiane

1,2-Dithiolane

1,3-Dithiolane

2-Ethyl-1,3-dithiane

2-Ethylidene-1,3-dithiane

Ethyl-2-thiopheneacetate

2-Methyl-3,4-dihydro-2H-thiopyran

5-Methyl-1,2,3,4-tetrathia-cyclohexane

5-Methyl 1,2,3-thiadiazole

4-Methyl-5-vinylthiazole

2-(1-Propenylthio)thiophene

Propylene sulfide

Tetrahydro-2,5-dimethylthiophene

2-(1-Thia-2-cyclohexen-6-yl)-1,3-dithia-cyclohex-5-ene

3-(2-Thia-4-pentenyl)-1-thiacyclohex-5-ene

Thiazole

Thiirane

2-Thiophenecarboxaldehyde

3-(2,3,4-Trithia-5-heptenyl)-1-thia-cyclohex-5-ene

1,3,5-Trithiane

3-Vinyl-1,2-dithiacyclohex-4-ene

2-Vinyl-1,3-dithiane

3-Vinyl-1,2-dithiane

2-Vinyl-4H-1,3-dithiine

3-Vinyl-4H-1,2-dithiine

2-Vinylthiophene

Other compounds

Acetaldehyde

Acetone

Allyl alcohol

Aniline

2-Butenal

2,4-Dimethylfuran

2,3-Dimethylpyrazine

2,5-Dimethylpyridine

2,5-Dimethylpyrazine

2,6-Dimethylpyrazine

2-Ethyl-2-butenal

Ethylpyrazine

Heptadecene
Fresh garlic (Refs.)

Heated garlic (Refs.)

$(17,47-50)$

$(17,24,44,51)$

$(17,24)$

$(47,51)$

$(44,47,51)$

(51)

$(34,38,53,54)$

$(38,51,54)$ 
Table I. Continued.

\begin{tabular}{lcc}
\hline Compound & Fresh garlic (Refs.) & Heated garlic (Refs.) \\
\hline 4-Heptenal & $(24,44)$ & $(38,53)$ \\
2,4-Hexadienal & $(44,47)$ & \\
Hexanal & $(44)$ & \\
1-Hexanol & $(17)$ & \\
2-Hexanol & $(44)$ & $(51)$ \\
5-Hexenal & $(44)$ & $(54)$ \\
5-Hexen-2-one & $(44)$ & $(54)$ \\
1-Hydroxy-4-methyl-2,6-di-tert-butylbenzene & $(51)$ & $(38)$ \\
Isobutyl isothiocyanate & $(17)$ & $(38,54)$ \\
Methoxymethyl isothiocyanate & $(47)$ & $(38)$ \\
2-Methylbenzaldehyde & $(17)$ & \\
3-Methylbutanal & $(44)$ & $(38)$ \\
2-Methyl-2-butenal & $(47)$ & $(38)$ \\
3-Methyl-2-cyclopentene-1-thione & $(17)$ & $(58)$ \\
2-Methyl-5-ethylpyridine & & \\
2-Methylene-4-pentenal & $(44,47)$ & \\
2-Methylfuran & $(47)$ & $(51)$ \\
2-Methyl-3-pentanol & $(24)$ & \\
2-Methyl-4-pentenal & $(44,47)$ & \\
2-Methylpyridine & & \\
3-Methylpyridine & $(47)$ & \\
1-Methyl-3-pyrrolin-2-one & $(51)$ & \\
Pentadecene & $(49)$ & $(51)$ \\
2-Pentenal & $(47)$ & \\
3-Penten-2-one & $(44)$ & \\
Phenylethyl butyrate & $(51)$ & \\
Propene & $(17)$ & \\
2-Propen-1-ol & $(51)$ & \\
Pyridine & $(51)$ & \\
Sulfur dioxide & & \\
Trimethylpyrazine & & \\
\hline
\end{tabular}

as diallyl, methyl allyl, and diethyl mono-, di-, tri-, tetra-, penta- and hexasulfides, vinyldithiins, and $(E)$ - and $(Z)$ ajoene $(13,14,17)$.

Analytical methods markedly influence the results of the composition and number of compounds detected. Auger's study group used several different methods for isolating the compounds, including extraction, trapping techniques and hyphenated chromatographic procedures (18-23). According to their reports, allium odors contain only thiopropanal $S$-oxide and thiosulfinates as sulfur volatiles (23). Lee et al (2003) reported a comparison of the flavor composition of cut garlic obtained by either steam distillation (SD), simultaneous distillation and solvent extraction (SDE), solid-phase trapping solvent extraction (SPTE), or headspace solid-phase microextraction (HS-SPME) (24). Diallyl disulfide, allylsulfide and diallyl trisulfide were the predominant flavor components of SDE extract, whereas only diallyl disulfide was dominant in the SD, SPTE and HS-SPME extracts. The data were also analyzed to examine the association of fresh garlic aroma and considered not only diallyl disulfide, but also dithiin and allicin. Quantitative HPLC analysis of SD extracts and acetonitrile from commercial garlic, identified 20 different organosulfur compounds, including minor compounds such as 3-vinyl-4H-1,2-dithiin and 2-vinyl-4H-1,3-dithiin. Another analysis of oil-macerated garlic revealed that the samples contained (E)- and (Z)- ajoene, 3-vinyl-4H-1,2-dithiin and 2-vinyl-4H-1,3-dithiin as the major compounds (25). Abu-Lafi et al subsequently confirmed these results using experimental data obtained by GC-MS and HPLC chromatograms, and concluded that 3-vinyl-4H-1,2-dithiin and 2-vinyl-4H-1,3-dithiin were the major components of fresh garlic (26). However, it has been reported that these two sulfur cyclic compounds are artifacts formed from allicin during thermal gas chromatographic (GC) analysis $(15,27)$. In our study, although these dithiins were detected as artifacts on $\mathrm{GC}$ analysis, we could not deny the possibility that they contributed to the fresh odor of garlic (Abe et al, unpublished data). Allicin is converted by water into organosulfur compounds at room 
Table II. Comparison of volatile components between black garlic and aged garlic extract.

Black garlic

Compound

Sulfur containing compounds

2-Acetylthiazole

Allyl mercaptane

Allyl methyl disulfide

Allyl methyl sulfide

Allyl methyl trisulfide

Allyl propyl disulfide

Allyl propyl sulfide

Benzothiazole

Diallyl disulfide

Diallyl sulfide

Diallyl tetrasulfide

Diallyl trisulfide

Dimethyl disulfide

Dimethyl trisulfide

1,3-Dithiane

Methional

5-Methyl-2-thiophenecarboxaldehyde

2-Vinyl-4H-1,3-dithiin

3-Vinyl-4H-1,2-dithiin

Acids

Octanoic acid

Esters

Ethy acetate

Ethyl butanoate

Ethyl 2-butenoate

Lactones

3-Hydroxy-4,5-dimethyl-2(5H)-furanone

$\gamma$-Octalactone

Aldehydes

Benzaldehyde

Benzeneacetaldehyde

Furfural

Hexanal

5-Hexanal

2-Methylene-4-pentenal

2-Methylpropanal

3-Methylbutanal

3-Methylbutanal

5-Methylfurfural

Nonanal

Vanillin

Ketones

Acetone

2-Acetylfuran

2,3-Butanedione

2-Hydroxy-3-methyl-2-cyclopentenone

1-Hydroxy-2-propanone

3-Penten-2-one
(\%)

6.4

Aged garlic extract ${ }^{\mathrm{b}}$

$(\mathrm{mg} / \mathrm{l})$

0.03

1.1

18.2

0.66

1.37

0.50

0.04

0.15

0.33

0.84

1.88

6.29

0.11

0.86

1.39

0.65

0.02

0.06

0.92

0.03

0.15

0.19

0.13

7.00

0.03

0.07

0.03

0.01

0.62

0.18

12

17.3

0.16

0.29

14.9

2.8

8.8

3.0

0.53

0.02

0.54

0.15

0.91

0.03 
Table II. Continued.

Black garlic ${ }^{\mathrm{a}}$

(\%)

Compound

\section{Alcohols}

Phenylethyl alcohol

2-Propen-1-ol

Phenols

4-Ethylphenol

Eugenol

2-Methoxyphenol

Nitrogen containing compounds

2,3-Dimethylpyrazine

Trimethyloxazole

Trimethyl pyrazine
Aged garlic extract ${ }^{\mathrm{b}}$ $(\mathrm{mg} / \mathrm{l})$

${ }^{\mathrm{a}}$ Relative concentration of volatile compounds in black garlic (44). ${ }^{\mathrm{b}}$ Concentrations of the majority of the odor active compounds in aged garlic extract (Abe et al, unpublished data).

temperature or heating $(28,29)$, which may result in the aroma of fresh garlic changing more rapidly than expected.

GC methods are generally used for the analysis of the volatile compounds. Due to their reactive characteristics, some aroma compounds of garlic may be converted to artifacts during GC analysis. However, sensory-guided studies, such as GC-olfactometry (GC-O) are a useful tool for the analysis of key aroma compounds in a food matrix $(30,31)$. We analyzed the SDE of fresh garlic using aroma extract dilution analysis (AEDA) by GC-O equipped with a cool-on column, which prevents the decomposition of volatiles in the GC injection port to characterize the aroma active components. We identified 18 aroma compounds with a flavor dilution factor (FD factor) $\geq 1$ (Abe et al, unpublished data). The highest FD factor was obtained for 2-vinyl-4H-1,3-dithiin (pungent, $\mathrm{FD}=65536$ ). The FD factors of the other odorants ranged from 1,024 to 128 as follows: Unknown compound (potato, earthy, $\mathrm{FD}=1,024), S$-methyl methanethiosulfinate (radish, FD=256), unknown compound (aniseed-like, FD=256), methional (cooked potato, FD=128) and 3-vinyl-4H-1,2-dithiin (garlic, $\mathrm{FD}=128$ ). Of these compounds, with the exception of the thiosulfinates, only methional was shown to have a high FD factor. Based on these results, although the pungent odor of fresh garlic can be attributed mainly to thiosulfinates, their degradation products also seemed to be contributors of fresh garlic aroma as well.

\section{Nature of volatile compounds in garlic cloves during heating}

Garlic is used worldwide in the home and in the industry in several types of products, such as garlic oil, garlic powder, garlic salt, garlic paste and garlic flakes. These products are prepared by various cooking treatments, including soaking in water or oil, roasting, steaming, or drying. The products may undergo further changes during cooking when used as spices or seasoning in dishes. This section focuses on how the aroma of fresh garlic is altered or transformed by processing, particularly heating.

There are several reports on the analysis of volatile components in cooked garlic samples $(32,33)$. Locatelli et al described the profiles of organosulfur compounds, including allicin, $E$ or $Z$-ajoene, dithiins, diallyl sulfide, diallyl disulfide and diallyl trisulfide, in the solvent extraction of pre-cooked (chopped, sliced and whole cloves) and cooked (simmering, rolling boiled and stir-fried) garlic with dichloromethane using HPLC analysis (34). Their results indicated that the allicin content could be determined in pre-cooked samples, while cooking significantly influenced the diallyl disulfide and diallyl trisulfide levels. These two compounds exhibited the highest levels with an increased treatment temperature (rolling boil and stir-fried). It has been previously reported that thisulfinates are very unstable and are transformed into polysulfides in water or into vinyldithiins in hexane, ether or vegetable oil (35-37).

Yu et al (1993) investigated the volatile compounds in the SD-solvent extraction of deep-oil fried, microwave-heated and oven-baked sliced garlic with using normal GC analysis (38). They reported that thiosulfinates, which contribute to and are precursors of the fresh aroma of raw garlic, were destroyed by these heating processes, and that thermally-treated garlic aroma consisted of i) acrylic sulfur-containing compounds, such as thiol and sulfide; ii) cyclic sulfur-containing compounds, such as thiophenes and vinyldithiins; iii) nitrogen-containing compounds, pyridine and pyrazine which contain one and two nitrogen atoms on the benzene ring; and iv) oxygen-containing compounds, such as aldehydes and alcohols. Diallyl disulfide and diallyl trisulfide were found to be the dominant compounds in baked and microwave-baked garlic samples. Diallyl disulfide was also found to be the dominant compound in fried, oil-cooked and microwave-fried garlic samples; however, the content of diallyl trisulfide was very low. In addition, the levels of vinyldithiins, allyl alcohols and oxygen-containing and nitrogen-containing volatile compounds were higher in 
fried samples than in baked samples. It has been reported that vinyldithiins are transformed from allicin into a non-polar solvent (37) and therefore, it would be expected that the level of these compounds would be increased in oil-cooked samples.

During the heating process of garlic, it is postulated that sulfur containing compounds are mainly decomposed and/or rearranged to products of alk(en)yl thisulfinates, and nitrogen-containing volatile compounds, such as pyridines and pyrazines. These compounds never exist in fresh cloves and are formed in fried or baked garlic as a result of the Maillard reaction that occurs during high temperature thermal treatment.

\section{Comparison of volatile components between black garlic and aged garlic extract}

The aging process provides a number of benefits to improve functional properties. Garlic is no exception to this process; black garlic is produced by the thermal processing of fresh garlic for several months at $60-80^{\circ} \mathrm{C}$ under controlled humidity without additives (39). Aged garlic extract (AGE) and other aged types of garlic prepared by soaking sliced cloves in an aqueous ethanol solution or the extraction of cloves aged for several months at an ambient temperature are also available in markets (40). The diverse bioactivities of the aged garlic which were prepared by those two conditions have been described in many scientific reports (41-43). Below, the volatile compounds of AGE are shown and compared to those of black garlic in order to clarify the effects of the aging process on the formation of these compounds.

Table II presents the composition of volatile compounds in black garlic obtained by fermentation in a closed chamber for 5 weeks under high humidity at $60-80^{\circ} \mathrm{C}(44)$, and AGE prepared by soaking sliced garlic cloves in an aqueous ethanol solution, or the extraction of cloves aged up to 10 months at room temperature in an air tight container (Abe et al, unpublished data). The volatile compounds in black garlic were analyzed by headspace-GC-MS. On the other hand, AGE was distilled by solvent-assisted flavor evaporation to separate the volatiles from the non-volatile material. The key aroma compounds in AGE were identified by AEDA and quantified by GC-MS using cold on-column injection method.

For sulfur-containing compounds, the aroma components in AGE revealed a similar trend as the volatile profile of black garlic. Allyl methyl sulfide was dominant in black garlic (18.2\%), followed by allyl methyl trisulfide (1.5\%), diallyl sulfide $(1.4 \%)$ and several organosulfur compounds. Diallyl sulfide was dominant in AGE $(6.29 \mathrm{mg} / \mathrm{l})$, followed by diallyl disulfide $(1.88 \mathrm{mg} / \mathrm{ml})$, diallyl trisulfide $(1.39 \mathrm{mg} / \mathrm{l})$ and several organosulfur compounds. These pungent smelling sulfides were considered to have been formed by the decomposition of thiosulfinates during the processing of fresh garlic. On the other hand, for non-sulfur-containing odorants, the aroma components of AGEdiffered markedly from those of black garlic. Aldehydes, such as furfural (17.3\%), 2-methylene-4-pentenal (14.9\%) and benzeneacetaldehyde (12\%) were the dominant compounds in black garlic, but were not the key aroma compounds in AGE. Furfural was detected by GC-MS in the volatile extract of AGE, but not by AEDA with a FD $\geq 1$. These findings indicated that furfural was not a key aroma component in AGE. Phenols, esters and nitrogen containing compounds were identified as key aroma components in AGE. These compounds were generated by aging, and exceeded their respective concentration which detectable by human nose. Three fruity-smelling esters (ethyl acetate, $7.00 \mathrm{mg} / \mathrm{l}$; ethyl 2-butenoate, $0.07 \mathrm{mg} / \mathrm{l}$; and ethyl butanoate, $0.03 \mathrm{mg} / \mathrm{l}$ ) were not detected in black garlic, but were identified as key aroma components in AGE. It is likely these esters were produced by the esterification of ethanol, which was used as a solvent during the aging process. Nutty or green-smelling nitrogen containing compounds (trimethyl pyrazine, $0.10 \mathrm{mg} / \mathrm{l}$; trimethyloxazole, $0.07 \mathrm{mg} / \mathrm{l}$; and 2,3-dimethylpyrazine, $0.02 \mathrm{mg} / \mathrm{l}$ ) that were not detected in black garlic were identified as key aroma components in AGE. These odorants are likely produced by the Maillard reaction during the aging process.

\section{Conclusion}

This review summarized the volatile components of fresh and processed garlic. The pungent odor of fresh garlic can be attributed mainly to thiosulfinates, as well as their degradation products seemed to be contributors for fresh garlic aroma. Although the volatile components of aging processed garlic were mainly consisted of sulfur-containing compounds, non-sulfur-containing compounds also associated with their aroma, which compositions and contents were different in type of aging process. Taken together, the findings of studies mentioned in this review indicate that slight variations in chemical reactions during the aging process may lead to differences in the aroma of two types of garlic, black garlic and AGE samples.

\section{Acknowledgements}

The authors would like to thank Dr Kazuki Toeda from the Tokyo University of Agriculture, for his critical reading of the manuscript.

\section{Funding}

No funding was received.

\section{Availability of data and materials}

Not applicable.

\section{Authors' contributions}

KA collected the data and constructed the tables. YH designed the study and revised the manuscript. TM designed the study and wrote the manuscript. All authors have read and approved the final manuscript.

\section{Ethics approval and consent to participate}

Not applicable.

\section{Patient consent for publication}

Not applicable. 


\section{Competing interests}

The authors declare that they have no competing interests.

\section{References}

1. Warade SD and Shinde KG: Garlic. In: Handbook of Vegetable Science and Technology: Production, Composition, Storage and Processing. Salunkhe DK and Kadam SS (eds). 1st edition. Marcel Dekker, New York, pp397-431, 1998.

2. Block E: The chemistry of garlic and onions. Sci Am 252: 114-119, 1985.

3. Lee EJ, Kim KS, Jung HY, Kim DH and Jang HD: Antioxidant activities of garlic (Allium sativum L.) with growinng districts. Food Sci Biotechnol 14: 123-130, 2005.

4. Whitmore BB, and Naidu AS: Thiosulfinates. In: Natural Food Antimicrobial Systems. Naidu AS (ed). CRC Press, Boca Raton, pp265-380, 2000

5. Shin NR, Kwon HJ, Ko JW, Kim JS, Lee IC, Kim JC, Kim SH and Shin IS: S-Allyl cysteine reduces eosinophilic airway inflammation and mucus overproduction on ovalbumin-induced allergic asthma model. Int Immunopharmacol 68: 124-130, 2019.

6. Block E: Flavorants from Garlic, Onion, and Other Alliums and Their Cancer-Preventive Properties. In: Food Phytochemicals for Cancer Prevention I. Vol. 546 American Chemical Society, pp84-96, 1993.

7. Kamel A and Saleh M: Recent studies on the chemistry and biological activities of the organosulfur compounds of garlic (allium sativum). Stud Nat Prod Chem 23: 455-485, 2000.

8. Miron T, Mironchik M, Mirelman D, Wilchek $M$ and Rabinkov A: Inhibition of tumor growth by a novel approach: In situ allicin generation using targeted alliinase delivery. Mol Cancer Ther 2: 1295-1301, 2003.

9. Stoll A and Seebeck E: Chemical investigations on alliin, the specific principle of garlic. Adv Enzymol Relat Subj Biochem 11: 377-400, 1951

10. Thompson JF, Turner DH and Gering RK: g-Glutamyl transpeptidase in plants. Phytochemistry 3: 33-46, 1964.

11. Ziegler SJ and Sticher O: HPLC of $S$-alk(en)yl- $L$-cysteine derivatives in garlic including quantitative determination of (+)-S-allyl- $L$-cysteine sulfoxide (alliin). Planta Med 55: 372-378, 1989.

12. Ueda Y, Sakaguchi M, Hirayama K, Miyajima R and Kimizuka A: Characteristic flavor constituents in water extract of garlic. Agric Biol Chem 54: 163-169, 1990.

13. Iberl B, Winkler G, Müller B and Knobloch K: Quantitative determination of allicin and alliin from garlic by HPLC. Planta Med 56: 320-326, 1990

14. Lawson LD, Wang ZYJ and Hughes BG: g-Glutamyl-S-alkylcysteines in garlic and other allium spp.: Precursors of age-dependent trans- 1-propenyl thiosulfinates. J Nat Prod 54: 436-444, 1991.

15. Block E: The organosulfur chemistry of the genus AlliumImplications for the organic chemistry of sulfur. Angew Chem Int Ed Engl 31: 1135-1178, 1992.

16. Block E, Naganathan S, Putman D and Zhao SH: Allium chemistry: HPLC analysis of thiosulfinates from onion, garlic, wild garlic (Ramsoms), leek, scallion, shallot, elephant (great-headed) garlic, chive, and chinese chive. Uniquely high allyl to methyl ratios in some garlic samples. J Agric Food Chem 40: 2418-2430, 1992.

17. Yu TH, Wu CM and Liou YC: Volatile compounds from garlic. J Agric Food Chem 37: 725-730, 1989.

18. Ferary S and Auger J: What is the true odour of cut Allium? Complementarity of various hyphenated methods: Gas chromatography-mass spectrometry and high-performance liquid chromatography-mass spectrometry with particle beam and atmospheric pressure ionization interfaces in sulphenic acids rearrangement components discrimination. J Chromatogr A 750: 63-74, 1996

19. Teyssier C, Amiot MJ,Mondy N, Auger J, Kahane R and Siess MH: Effect of onion consumption by rats on hepatic drug-metabolizing enzymes. Food Chem Toxicol 39: 981-987, 2001.

20. Mondy N, Duplat D, Christides JP, Arnault I and Auger J Aroma analysis of fresh and preserved onions and leek by dual solid-phase microextraction-liquid extraction and gas chromatography-mass spectrometry. J Chromatogr A 963: 89-93, 2002.
21. Arnault I, Christidès JP, Mandon N, Haffner T, Kahane R and Auger J: High-performance ion-pair chromatography method for simultaneous analysis of alliin, deoxyalliin, allicin and dipeptide precursors in garlic products using multiple mass spectrometry and UV detection. J Chromatogr A 991: 69-75, 2003.

22. Jaillais B, Cadoux F and Auger J: SPME-HPLC analysis of Allium lacrymatory factor and thiosulfinates. Talanta 50: 423-431, 1999.

23. Ferary S, Thibout E and Auger J: Direct analysis of odors emitted by freshly cut Allium using combined high-performance liquid chromatography and mass spectrometry. Rapid Commun Mass Spectrom 10: 1327-1332, 1996.

24. Lee SN, Kim NS and Lee DS: Comparative study of extraction techniques for determination of garlic flavor components by gas chromatography-mass spectrometry. Anal Bioanal Chem 377: 749-756, 2003 .

25. Lawson LD, Wang ZJ and Hughes BG: Identification and HPLC quantitation of the sulfides and dialk(en)yl thiosulfinates in commercial garlic products. Planta Med 57: 363-370, 1991.

26. Abu-Lafi S, Dembicki JW, Goldshlag P, Hanuš LO and Dembitsky VM: The use of the 'Cryogenic' GC/MS and on-column injection for study of organosulfur compounds of the Allium sativum. J Food Compos Anal 17: 235-245, 2004.

27. Block E, Naganathan S, Putman D and Zhao S-H: Organosulfur chemistry of garlic and onion: Recent results. Pure Appl Chem 65: 625-632, 1993.

28. Curtis ME, Jones PR, Sparkman OD and Cody RB: Determination of the presence or absence of sulfur materials in drywall using direct analysis in real time in conjunction with an accurate-mass time-of-flight mass spectrometer. J Am Soc Mass Spectrom 20: 2082-2086, 2009.

29. Bautista DM, Movahed P, Hinman A, Axelsson HE, Sterner O, Högestätt ED, Julius D, Jordt SE and Zygmunt PM: Pungent products from garlic activate the sensory ion channel TRPA1. Proc Natl Acad Sci USA 102: 12248-12252, 2005.

30. Ullrich $F$ and Grosch W: Identification of the most intense volatile flavour compounds formed during autoxidation of linoleic acid. Z Lebensm Unters Forsch 184: 277-282, 1987.

31. Grosch W: Determination of potent odourants in foods by Aroma Extract Dilution Analysis (AEDA) and Calculation of Odour Activity Values (OAVs). Flavour Fragrance J 9: 147-158, 1994.

32. Locatelli DA, Nazareno MA, Fusari CM and Camargo AB: Cooked garlic and antioxidant activity: Correlation with organosulfur compound composition. Food Chem 220: 219-224, 2017.

33. Torres-Palazzolo C, Ramirez D, Locatelli D, Manucha W, Castro $\mathrm{C}$ and Camargo A: Bioaccessibility and permeability of bioactive compounds in raw and cooked garlic. J Food Compos Anal 70: 49-53, 2018.

34. Locatelli DA, Altamirano JC, González RE and Camargo AB: Home-cooked garlic remains a healthy food. J Funct Foods 16: $1-8,2015$.

35. Iberl B, Winkler G and Knobloch K: Products of allicin transformation: Ajoenes and dithiins, characterization and their determination by HPLC. Planta Med 56: 202-211, 1990.

36. Yu TH and Wu CM: Stability of allicin in garlic juice. J Food Sci 54: 977-981, 1989.

37. Freeman F and Kodera Y: Garlic chemistry: Stability of $S$-(2-Propenyl) 2-Propene-1-sulfínothioate (allicin) in blood, solvents, and simulated physiological fluids. J Agric Food Chem 43: 2332-2338, 1995

38. Yu TH, Wu CM and Ho CT: Volatile compounds of deep-oil fried, microwave-heated, and oven-baked garlic slices. J Agric Food Chem 41: 800-805, 1993.

39. Kim JH, Nam SH, Rico CW and Kang MY: A comparative study on the antioxidative and anti-allergic activities of fresh and aged black garlic extracts. Int J Food Sci Technol 47: 1176-1182, 2012.

40. United States Pharmacopeial Convention I, United States Pharmacopoeia 38 Garlic Fluidextract USP 38-NF 33, United States Pharmacopeial Convention, Rockville, MD: 6052-6055, 2015. https://www.uspnf.com/sites/default/files/usp_pdf/EN/ USPNF/official-text/usp-38-2s-index.pdf.

41. Ried K, Travica N and Sali A: The effect of aged garlic extract on blood pressure and other cardiovascular risk factors in uncontrolled hypertensives: The AGE at Heart trial. Integr Blood Press Control 9: 9-21, 2016.

42. Imai J, Ide N, Nagae S, Moriguchi T, Matsuura H and Itakura Y: Antioxidant and radical scavenging effects of aged garlic extract and its constituents. Planta Med 60: 417-420, 1994.

43. Kyo E, Uda N, Kasuga S and Itakura Y: Immunomodulatory effects of aged garlic extract. J Nutr 131 (3s): 1075S-1079S, 2001. 
44. Molina-Calle M, Priego-Capote F and Luque de Castro MD Headspace-GC-MS volatile profile of black garlic vs fresh garlic: Evolution along fermentation and behavior under heating. Lebensm Wiss Technol 80: 98-105, 2017.

45. Tamaki K, Sonoki S, Tamaki T and Ehara K: Measurement of odour after in vitro or in vivo ingestion of raw or heated garlic, using electronic nose, gas chromatography and sensory analysis. Int J Food Sci Technol 43: 130-139, 2008.

46. Lemar KM, Turner MP and Lloyd D: Garlic (Allium sativum) as an anti-Candida agent: A comparison of the efficacy of fresh garlic and freeze-dried extracts. J Appl Microbiol 93: 398-405, 2002.

47. Calvo-Gómez O, Morales-López J and López MG: Solid-phase microextraction-gas chromatographic-mass spectrometric analysis of garlic oil obtained by hydrodistillation. J Chromatogr A 1036: 91-93, 2004.

48. Sowbhagya HB, Purnima KT, Florence SP, Appu Rao AG and Srinivas P: Evaluation of enzyme-assisted extraction on quality of garlic volatile oil. Food Chem 113: 1234-1238, 2009.

49. Kimbaris AC, Siatis NG, Pappas CS, Tarantilis PA, Daferera DJ and Polissiou MG: Quantitative analysis of garlic (Allium sativum) oil unsaturated acyclic components using FT-Raman spectroscopy. Food Chem 94: 287-295, 2006.
50. Mochizuki E, Yamamoto T, Komiyama $\mathrm{Y}$ and Nakazawa $\mathrm{H}$ : Identification of Allium products using flame photometric detection gas chromatography and distribution patterns of volatile sulfur compounds. J Agric Food Chem 46: 5170-5176, 1998.

51. Kim NY, Park MH, Jang EY and Lee J: Volatile distribution in garlic (Allium sativum L.) by solid phase microextraction (SPME) with different processing conditions. Food Sci Biotechnol 20: 775-782, 2011.

52. Castada HZ, Mirondo R, Sigurdson GT, Mónica Giusti M and Barringer S: Deodorization of garlic odor by spearmint, peppermint, and chocolate mint leaves and rosmarinic acid. Lebensm Wiss Technol 84: 160-167, 2017.

53. Kyung KH,Kim MH,Park MS andKim YS: Alliinase-independent inhibition of Staphylococcus aureus B33 by heated garlic. J Food Sci 67: 780-785, 2002.

54. Yu TH, Wu CM and Chen SY: Effects of $\mathrm{pH}$ adjustment and heat treatment on the stability and the formation of volatile compounds of garlic. J Agric Food Chem 37: 730-734, 1989.

This work is licensed under a Creative Commons

Attribution-NonCommercial-NoDerivatives 4.0 International (CC BY-NC-ND 4.0) License. 